\title{
Russia's scientific legacy
}

\author{
Many insights of Russian scientists are unknown or long-forgotten outside of Russia. Making the Russian \\ literature accessible to the international scientific community could stimulate new lines of research.
}

Space scientists from around the world gathered at the Lomonosov Moscow State University this past August for the fortieth scientific assembly of the Committee on Space Research (http://cospar2014moscow. com) amidst a tense political climate. Moscow is a complex city, where aging grandeur and pomp of past decades contrast with the bustle and construction of a modern metropolis. Similarly complex is Russia's scientific legacy: its history has evolved largely separate from the West, isolated by political differences and made inaccessible by language. Nevertheless, there are few countries with as strong a heritage in the space sciences as Russia.

Lomonosov Moscow State University one of the most prestigious in Russia was co-founded in 1755 by the scholar Mikhail Lomonosov, who is perhaps best known for his discovery of the Venusian atmosphere from observations of the transit of Venus across the Sun in 1761. Lomonosov's contributions to the geosciences, however, are less well known outside of Russia. His name is probably most familiar in the context of the submerged Lomonosov Ridge that runs across the centre of the Arctic Ocean. The ridge was discovered by Soviet expeditions in 1948 and lies at the heart of a territorial dispute between the nations bordering the Arctic (Nature Geosci. 2, 310-313; 2009). Meanwhile, however, Lomonosov's own contribution to Arctic research is little known. He explained the formation of icebergs in 1760 , before anyone else.

\section{At this time of renewed tensions ... it is especially important that the scientific divide of language and politics be lifted.}

In fact, Lomonosov is the author of one of the most important treatises of geology that those of us who were educated in the West have probably never heard of. On the Strata of the Earth was published in 1763 and many of the ideas put forth in the book predate - by a quarter century -

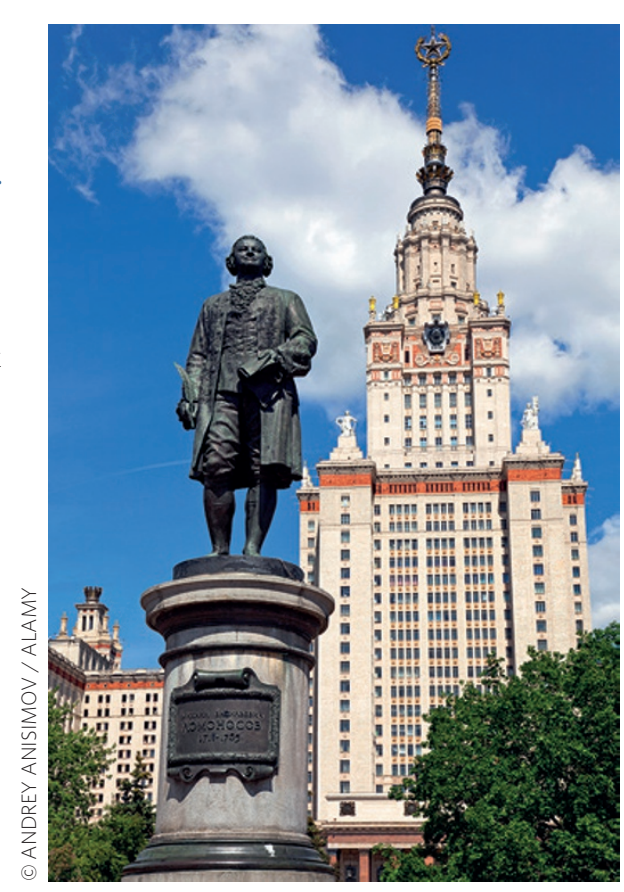

Statue of Lomonosov at Moscow State University.

similar theories from James Hutton and others considered today, in the West, to be the founders of modern geology. Instead of being heralded alongside his European counterparts, Lomonosov's contribution to the geosciences has been buried, partially due to the fact that On the Strata of the Earth, like Lomonosov's other texts, was published in Russian.

Russia had a rich scientific history from the mid-1700s. Fruitful investigations continued until the collapse of the Soviet Union in 1991 led to a reduction in research funding and caused many Russian scientists to head to western institutions. Much of this historical research is published in Russian-language journals, creating a language barrier to a broader international readership, a practice that continues to the present day.

A glimpse of the wealth of information hidden in the Russian-language archives was afforded us in the process of handling a paper in this issue of Nature Geoscience. On page 35, Aggarwal and co-authors report that groundwater discharge is the primary pathway for the degassing of radiogenic ${ }^{4} \mathrm{He}$ from the continental crust. However, in the course of the review process, it came to light that a potential role of groundwater flow in ${ }^{4} \mathrm{He}$ degassing is not an entirely new idea. The notion was presented 80 years ago, in a Russian-language journal (V. P. Savchenko, Nat. Gases 9, 53-197; 1935).

For the purpose of the review process, this pioneering 1935 Savchenko paper had to be tracked down and its key points translated by Russian language speakers to allow the authors to cite the paper and the reviewers and editors to assess the advance of the manuscript under consideration over the existing, albeit not readily accessible, literature.

Of course the sophisticated ${ }^{4} \mathrm{He}$ measurements and ${ }^{81} \mathrm{Kr}$ groundwater dating used by Aggarwal and co-authors were not available in 1935 . With the help of these modern techniques, a process that could only be hypothesized 80 years ago could be tackled quantitatively. As an added bonus, the research by Aggarwal and co-authors highlights a little-known piece of the Russian literature that will hopefully be considered in this field of research going forward.

But, apart from the occasional paper bubbling to the surface with a citation in an English language journal, the immense wealth of the Russian scientific literature remains largely unknown and inaccessible to researchers outside of Russia. More effort needs to be made to translate and digitize this rich body of research, so that the world's scientific community can build on these insights.

Lomonosov's On the Strata of the Earth was finally translated into English in 2012 (Special Paper 485, Geological Society of America, 2012) and thus integrated into the internationally accessible scientific literature. At this time of renewed tensions between Russia and the West over the annexation of the Crimean Peninsula, Ukraine and the risk of renewed isolation of Russian science, it is especially important that the scientific divide of language and politics be lifted so that the body of literature can grow from a stronger, united base. 